\title{
ChemComm
}

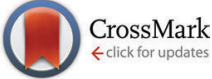

Cite this: Chem. Commun., 2016, 52,8463

Received 3rd May 2016 Accepted 9th June 2016

DOI: $10.1039 / \mathrm{c} 6 \mathrm{cc0} 03680 \mathrm{e}$

www.rsc.org/chemcomm

\section{Are two better than one? Comparing intermolecular and intramolecular indicator displacement assays in pyrophosphate sensors $\dagger$}

\author{
Xuejian Liu, David G. Smith and Katrina A. Jolliffe*
}

Peptide receptors with Zn(II)-DPA units and a covalently bound fluorescent coumarin indicator on an oxazole-containing scaffold are shown to function as more selective pyrophosphate sensors than the analogous chemosensing ensembles in indicator displacement assays.

Anions play crucial roles in biological processes. Pyrophosphate $\left(\mathrm{P}_{2} \mathrm{O}_{7}{ }^{4-}\right.$, $\left.\mathrm{PPi}\right)$ for example, plays an important role in bioenergetics and metabolic processes. As such, the selective recognition and sensing of biologically relevant anions in water has numerous potential applications. For example, a sensor able to selectively detect pyrophosphate (PPi) in the presence of other phosphate species, especially nucleoside triphosphates, in aqueous solution would find use in bioanalytical applications. ${ }^{1-11}$

A number of recent studies have shown that receptors containing Zn(II)-dipicolylamino (DPA) units exhibit high selectivity and affinity towards phosphate oxoanions in water, and in some cases are able to discriminate between these species. ${ }^{1,12-15}$ We have previously reported oxazole-based cyclic peptide receptors with $\mathrm{Zn}$ (II)-DPA binding sites that show high levels of discrimination for $\mathrm{PPi}^{16}{ }^{16}$ as monitored through either colourimetric ${ }^{17}$ or fluorescent ${ }^{18,19}$ indicator displacement assays (IDAs). IDAs have been used successfully as a means of sensing anions in numerous chemosensing ensembles. ${ }^{9,20-25}$ However, for some applications it would be preferable to use sensors in which the indicator is covalently attached to the anion recognition moiety.

Intramolecular IDAs, in which the indicator is covalently attached to the receptor, provide a novel means by which to create molecular sensors. ${ }^{26}$ We report here a small family of oxazole-based peptides (1-3. $\left.\mathbf{Z} \mathbf{n}_{\mathbf{2}}\right)$, with $\mathrm{Zn}$ (II)-DPA anion binding sites, to which a fluorescent coumarin indicator is covalently bound through a flexible linker, so that it can act as an

School of Chemistry, The University of Sydney, NSW 2006, Australia.

E-mail: kate.jolliffe@sydney.edu.au; Fax: +61 29351 3329; Tel: +61 293512297

$\dagger$ Electronic supplementary information (ESI) available: Synthetic procedures and NMR spectra for new compounds, experimental procedures, anion titration data, pyrophosphatase assay data. See DOI: 10.1039/c6cc03680e intramolecular fluorescent IDA (Fig. 1). We also compare the ability of these molecules to bind selectively to pyrophosphate with that of the analogous receptors in intermolecular IDAs with a comparable coumarin indicator.

Based on our previous studies, in which we found that chemosensing ensembles comprising receptors $\mathbf{4} \cdot \mathbf{Z n}_{2}$ or $\mathbf{5} \cdot \mathbf{Z n}_{2}$ with a variety of indicators including coumarin sulfonate $\mathbf{6}$ (Fig. 2), showed good selectivity for pyrophosphate over other phosphate oxoanions in aqueous solution,,$^{9,17-19}$ we designed three receptors, $\mathbf{1} \cdot \mathbf{Z n}_{2}, \mathbf{2} \cdot \mathbf{Z n}_{\mathbf{2}}$ and $\mathbf{3} \cdot \mathbf{Z n}_{2}$ comprising an oxazolecontaining peptide backbone with two side-chain appended Zn(II)-DPA binding sites and a coumarin fluorophore attached via a side-chain triazole moiety. $\mathbf{1} \cdot \mathbf{Z n}_{\mathbf{2}}$ and $\mathbf{2} \cdot \mathbf{Z n}_{\mathbf{2}}$ differ structurally in the order of the side chain appendages. In $\mathbf{1} \cdot \mathbf{Z n}_{\mathbf{2}}$ the Zn(II)-DPA units are adjacent to one another whereas in $\mathbf{2} \cdot \mathbf{Z n _ { 2 }}$ the coumarin is located in between them. $\mathbf{3} \cdot \mathbf{Z n}_{\mathbf{2}}$ is a linear analogue, designed to ascertain whether the cyclic peptide structure is required to maintain high selectivity.

Compounds 1-3 were prepared using methods similar to those previously described (see ESI $\dagger$ for full synthetic schemes). ${ }^{8,9,15,17,25,27}$ Briefly, the synthesis of the linear precursors was achieved using standard solid phase peptide synthesis techniques with the appropriate oxazole building blocks (7 and 8) (Fig. 2) and using Fmoc/HATU chemistry. The linear precursors to compounds 1 and 2 were prepared staring from 2-chlorotritylchloride resin, while for $\mathbf{3}$, the linear peptide was extended from Rink amide resin to provide the C-terminal amide upon cleavage from the resin. For the synthesis of $\mathbf{1}$ and 2, cleavage of the linear precursors from the resin was followed by solution phase cyclisation using the coupling reagent DMTMM-BF $\mathrm{B}_{4}$. For all three peptides, the coumarin indicator was then attached via a copper(I)catalysed azide-alkyne [3+2] cycloaddition (CuAAC) reaction ${ }^{28,29}$ with azide 9. The $\mathrm{Cbz}$ protecting groups were then removed using a solution of hydrogen bromide in acetic acid to give the corresponding diamines after basic workup. These were then subjected to reductive amination with 2-pyridinecarboxaldehyde using our previously established conditions, providing the DPAfunctionalised cyclic peptide over two steps. Subsequent addition 

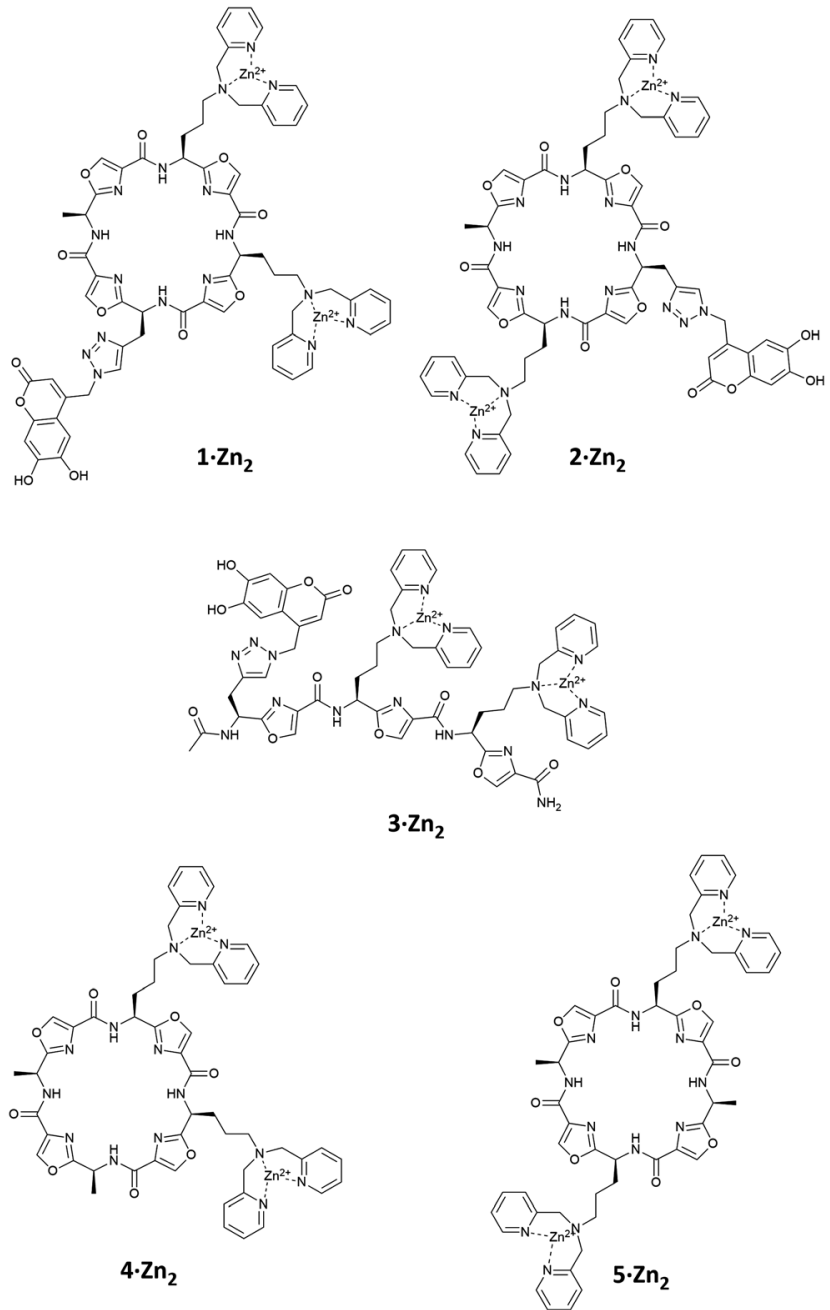

Fig. 1 Structures of peptide-based receptors $\mathbf{1 - 3} \cdot \mathbf{Z} \mathrm{n}_{\mathbf{2}}$, and the previously reported $\mathbf{4}-\mathbf{5} \cdot \mathbf{Z n _ { 2 }}$

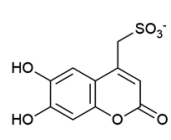

6

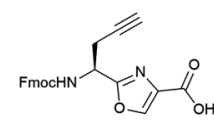

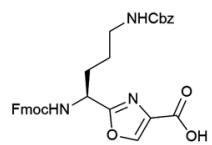

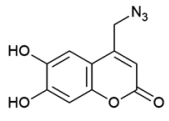

9
Fig. 2 Oxazole building blocks $\mathbf{7}$ and $\mathbf{8}$, and coumarin derivatives $\mathbf{6}$ and $\mathbf{9}$.

of two equivalents of $\mathrm{Zn}\left(\mathrm{NO}_{3}\right)_{2}$ gave the fully functionalised anion receptors, $\mathbf{1}-\mathbf{3} \cdot \mathbf{Z n _ { 2 }}$.

The anion binding behaviour of peptides $\mathbf{1}-\mathbf{3} \cdot \mathbf{Z n} \mathbf{n}_{\mathbf{2}}$ was then assessed by titration and compared to that of chemosensing ensembles comprising either $\mathbf{4} \cdot \mathbf{Z n}_{2}$ or $\mathbf{5} \cdot \mathbf{Z n}_{\mathbf{2}}$ and coumarin indicator $6^{24}$ under the same conditions. PPi, ADP and ATP were incrementally added to a solution of $\mathbf{1}-\mathbf{3} \cdot \mathbf{Z} \mathbf{n}_{\mathbf{2}}$ in HEPES buffer (5 mM, $145 \mathrm{mM} \mathrm{NaCl}, \mathrm{pH} 7.4$ ) at $25{ }^{\circ} \mathrm{C}$ and the fluorescence emission recorded after each addition. In each case, addition of the anion resulted in an increase in fluorescence intensity, suggesting that binding of the anion resulted in displacement of the coumarin from the Zn(II)-DPA units with concomitant increase of fluorescence intensity (Fig. 3 and ESI $\dagger$ ).
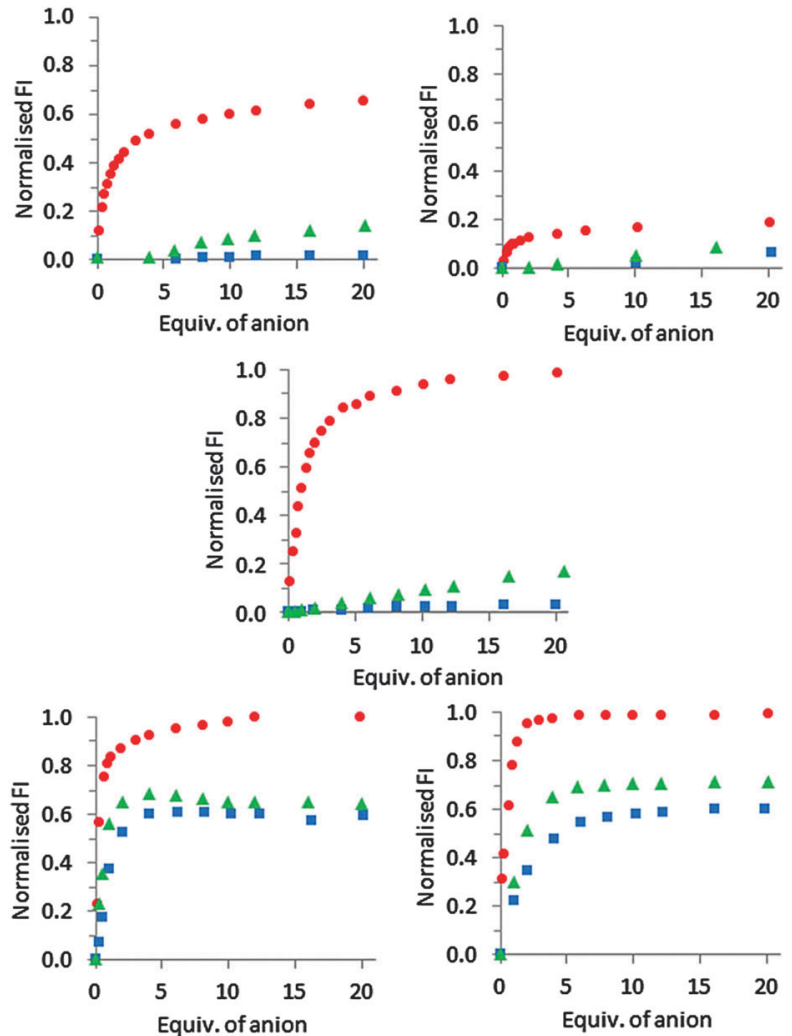

Fig. 3 Changes in the fluorescence emission intensity of $\mathbf{1} \cdot \mathbf{Z} \mathbf{n}_{\mathbf{2}}$ (top left), $\mathbf{2} \cdot \mathbf{Z} \mathbf{n}_{\mathbf{2}}$ (top right), $\mathbf{3} \cdot \mathbf{Z} \mathbf{n}_{\mathbf{2}}$ (middle), $\mathbf{4} \cdot \mathbf{Z} \mathbf{n}_{\mathbf{2}}$ (bottom left) and $\mathbf{5} \cdot \mathbf{Z} \mathbf{n}_{\mathbf{2}}$ (bottom right) at $480 \mathrm{~nm}$ upon addition of $\operatorname{PPi}(\bullet), \operatorname{ATP}(\mathbf{\Lambda})$, and $\operatorname{ADP}(\boldsymbol{\square})$ in HEPES buffer ( $5 \mathrm{mM}, 145 \mathrm{mM} \mathrm{NaCl}, \mathrm{pH} 7.4)$ at $25^{\circ} \mathrm{C}$.

For receptor $\mathbf{1} \cdot \mathbf{Z n}_{2}$, addition of PPi resulted in around a 6.5 -fold fluorescent enhancement, accompanied by a $10 \mathrm{~nm}$ bathochromic shift (Fig. 4). Fitting of the titration data to a $1: 1$ binding model gave a $\log K=5.2$ as determined by a nonlinear least squares curve fitting. In contrast, addition of ADP or ATP induced only a minor fluorescence increase when added to $\mathbf{1} \cdot \mathbf{Z n}_{2}$ (Fig. 3 and ESI $\dagger$ ), indicating that $\mathbf{1} \cdot \mathbf{Z n}_{\mathbf{2}}$ exhibits a selective turn-on fluorescence response in the presence of PPi.

The response of receptor $\mathbf{2} \cdot \mathbf{Z n}_{2}$ to PPi shows a similar $10 \mathrm{~nm}$ bathochromic shift, although the increase in emission intensity is much smaller compared to that observed for $\mathbf{1} \cdot \mathbf{Z n}_{2}$, indicating $\mathbf{2} \cdot \mathbf{Z n}_{\mathbf{2}}$ is less sensitive towards PPi than $\mathbf{1} \cdot \mathbf{Z n}_{\mathbf{2}}$ (Fig. 3). In addition, similar fluorescent enhancements are observed for addition of ATP and ADP to $\mathbf{2} \cdot \mathbf{Z} \mathbf{n}_{2}$ as are observed for PPi addition, indicating that $\mathbf{2} \cdot \mathbf{Z n}_{\mathbf{2}}$ is less selective towards PPi over ADP and ATP than $1 \cdot \mathbf{Z n}_{2}$.

These results suggest that the positioning of the two Zn(II)-DPA binding sites relative to the coumarin indicator on the cyclic peptide scaffold has a significant influence on anion binding capability. Positioning the indicator between the two Zn(II)-DPA units appears to make intramolecular indicator displacement more difficult, presumably as a result of stronger interactions between the coumarin and the $\mathrm{Zn}$ (II)-DPA units. This is attributed to the ability of the indicator to bridge both $\mathrm{Zn}$ (II)-DPA binding sites in this configuration. Positioning the two $\mathrm{Zn}$ (II)-DPA binding 


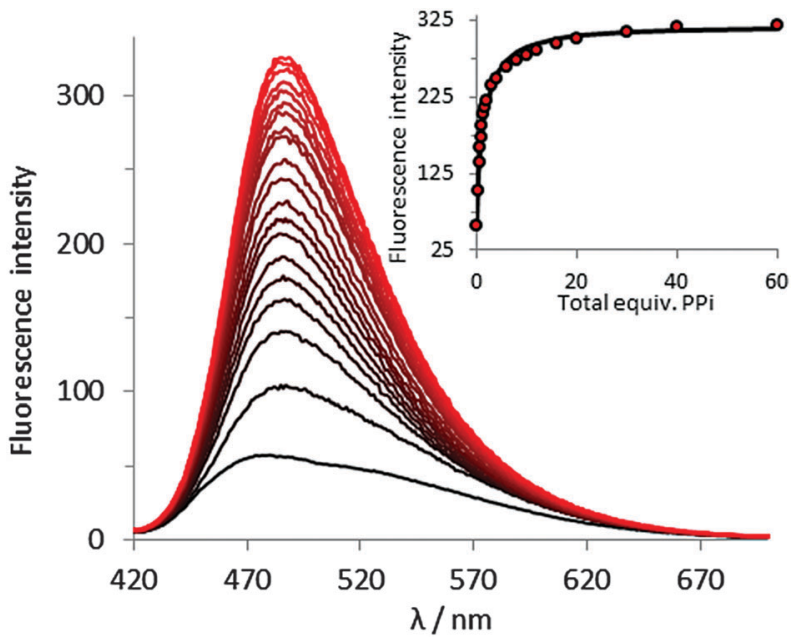

Fig. 4 Fluorescence emission spectra of $\mathbf{1} \cdot \mathbf{Z n}_{\mathbf{2}}(5 \mu \mathrm{M})$ in response to PPI $(0-300 \mu \mathrm{M})$ in HEPES $(5 \mathrm{mM}, 145 \mathrm{mM} \mathrm{NaCl}, \mathrm{pH} 7.4)$ at $25^{\circ} \mathrm{C}$. $\lambda_{\mathrm{ex}}=390 \mathrm{~nm}$, slits $=5 \mathrm{~nm} / 5 \mathrm{~nm}$. Inset: Binding isotherm (-) obtained by fitting the observed fluorescence intensities at $480 \mathrm{~nm}(\bullet)$ to a 1:1 binding model using non-linear regression.

sites adjacent to each other on the peptide scaffold is required to achieve selective PPi binding in the intramolecular IDA, and may be attributed to indicator-metal interactions with only one of the $\mathrm{Zn}$ (II)-DPA units making the indicator easier to displace in $\mathbf{1} \cdot \mathbf{Z n}_{\mathbf{2}}$ than in $\mathbf{2} \cdot \mathbf{Z n}_{\mathbf{2}}$.

This is supported by the behaviour observed for $\mathbf{3} \cdot \mathbf{Z n}_{2}$, in which the Zn(II)-DPA units are also adjacent to one another, and the coumarin occupies a terminal position. This shows a very similar overall profile with respect to the three anions as observed for $\mathbf{1} \cdot \mathbf{Z n}_{2}$ (Fig. 3 and ESI $\dagger$ ). There is a large fluorescent enhancement in the presence of PPi, but minimal changes in emission upon the addition of either ADP or ATP. The emission maxima for $\mathbf{3} \cdot \mathbf{Z} \mathbf{n}_{\mathbf{2}}$ exhibits a blue shift upon PPi addition, compared to a red shift for $\mathbf{1} \cdot \mathbf{Z n}_{\mathbf{2}}$ and $\mathbf{2} \cdot \mathbf{Z n}_{2}$. This results from the difference in the initial emission maxima, observed at $525 \mathrm{~nm}$ and $480 \mathrm{~nm}$ for $\mathbf{1} \cdot \mathbf{Z n}_{2}$ and $\mathbf{3} \cdot \mathbf{Z n}_{2}$, respectively which can be attributed to differences in the modes of binding from the coumarin indicator to the zinc(II) centres as a result of the different geometries of these molecules. Upon addition of PPi, both result in fluorescence with an emission maximum of $490 \mathrm{~nm}$.

As previously observed for a $1: 1$ mixture of $\mathbf{5} \cdot \mathbf{Z n}_{2}$ and coumarin indicator $6,{ }^{18}$ addition of PPi, ATP and ADP to chemosensing ensembles of either $\mathbf{4 \cdot Z \mathbf { n } _ { 2 }}$ or $\mathbf{5 \cdot Z \mathbf { n } _ { 2 }}$ and $\mathbf{6}$ all resulted in indicator displacement with an observed increase in fluorescence (Fig. 3 and

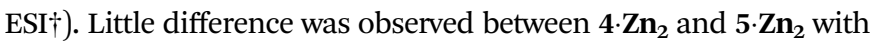
similar binding affinities for all three anions observed for both chemosensing ensembles (apparent $\log K_{\mathrm{a}}$ for $\mathbf{5} \cdot \mathbf{Z n _ { 2 }}$ for PPi = 6.8; ATP $=6.3$ and ADP $=6.0),{ }^{18}$ and both $4 \cdot \mathbf{Z n}_{2}$ and $\mathbf{5} \cdot \mathbf{Z n}_{2}$ showed a slight preference for binding to PPi over ATP and ADP.

A comparison of the results for $\mathbf{1} \cdot \mathbf{Z n}_{2}$ and $\mathbf{2 \cdot} \cdot \mathbf{Z n}_{2}$, with covalently attached indicators, to those obtained for $\mathbf{4} \cdot \mathbf{Z n} \mathbf{n}_{\mathbf{2}}$ and $\mathbf{5} \cdot \mathbf{Z n} \mathbf{n}_{\mathbf{2}}$, which use intermolecular indicator displacement assays to observe binding, suggests that by covalently attaching the coumarin derived indicator to the receptor a significant improvement in

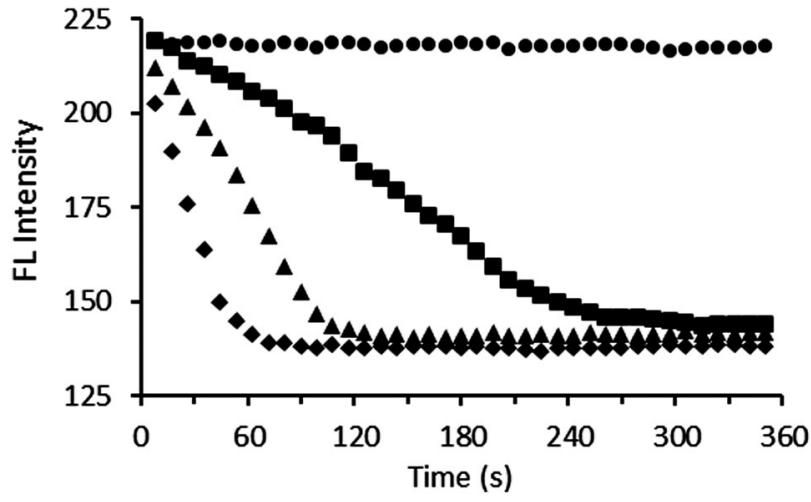

Fig. 5 Real-time assay of PPi $(80 \mu \mathrm{M})$ hydrolysis catalysed by different amounts of pyrophosphatase ( $\mathbf{O}=0$ units, $\mathbf{\square}=0.5$ units, $\boldsymbol{\Delta}=1.0$ units, $\boldsymbol{\nu}=2.0$ units) in the presence of $\mathbf{3} \cdot \mathbf{Z n}_{\mathbf{2}}(15 \mu \mathrm{M})$ in Tris buffer $(10 \mathrm{mM}$, $10 \mathrm{mM} \mathrm{MgCl}_{2}, \mathrm{pH} 7.5$ ) at $30{ }^{\circ} \mathrm{C}, \lambda_{\text {ex }}=390 \mathrm{~nm}$, slits $=5 \mathrm{~nm}$ \& $5 \mathrm{~nm}$.

selectivity for PPi can be obtained, albeit with lower sensitivity. $\mathbf{1} \cdot \mathbf{Z n}_{2}$ shows significantly higher selectivity for PPi compared to the analogous $\mathbf{4} \cdot \mathbf{Z} \mathbf{n}_{2}$, although the $\log K_{\mathrm{a}}$ for PPi is an order of magnitude lower for $\mathbf{1} \cdot \mathbf{Z n}_{\mathbf{2}}$ compared to that observed for $\mathbf{4} \cdot \mathbf{Z n _ { 2 }}$. However, the improved selectivity requires the indicator to be attached at the correct position on the scaffold, with $\mathbf{2} \cdot \mathbf{Z n}_{2}$ not displaying an improvement in either affinity or selectivity over the analagous indicator displacement approach with $\mathbf{5} \cdot \mathbf{Z n}_{\mathbf{2}}$. In terms of sensitivity, the titration data for both $\mathbf{1} \cdot \mathbf{Z n _ { 2 }}$ and $\mathbf{3} \cdot \mathbf{Z n} \mathbf{n}_{\mathbf{2}}$ indicate that a $5 \mu \mathrm{M}$ solution of these receptors can detect PPi anions at low micromolar levels, whereas it has previously been suggested that $\mathbf{5} \cdot \mathbf{Z n}_{\mathbf{2}}$ is capable of detection of nanomolar concentrations of PPi. ${ }^{19}$

One potential application of fluorescent PPi sensors is to monitor enzymatic processes. Pyrophosphatase is an enzyme which catalyses the hydrolysis of PPi to two phosphate ions in the presence of magnesium. To verify the general capability of our peptide-derived PPi sensors for real time monitoring of enzymatic processes, a fluorescence assay was used to monitor pyrophosphatase activity.

Pyrophosphatase was added to a solution containing either $\mathbf{1} \cdot \mathbf{Z n}_{2}$ or $\mathbf{3} \cdot \mathbf{Z n}_{2}$, and excess PPi in Tris buffer at $30{ }^{\circ} \mathrm{C}$. Differing quantities of PPi were used with each sensor, based upon the differing sensitivities exhibited by the two sensors. The fluorescence response was then measured at regular time intervals. Addition of pyrophosphatase resulted in a decrease in fluorescence intensity (emission was monitored at $485 \mathrm{~nm}$ ), with a more rapid decrease observed in the presence of larger quantities of enzyme (Fig. 5). This is consistent with a reduction in PPi concentration as the enzyme binds to and breaks down the PPi. The coumarin can then bind to the zinc centres of $\mathbf{1} \cdot \mathbf{Z n}_{2}$ or $\mathbf{3} \cdot \mathbf{Z n}_{2}$, resulting in quenching of the fluorescence emission. These enzyme assay results suggest the general applicability of peptide PPi sensors for monitoring the enzymatic process of inorganic pyrophosphatase.

In summary, we have developed oxazole-based peptide receptors which incorporate a covalently linked fluorescent coumarin reporter. This allows the receptor to function as an intramolecular indicator displacement assay, and to selectivity detect PPi. Compared to an intermolecular analogue, we observed 
greatly enhanced selectivity for PPi over competing phosphate species using systems with covalently attached indicators. We have demonstrated an application of these receptors to measure pyrophosphatase enzyme activity in real time.

We thank the ARC (DP110100682 and DP140100227) for financial support.

\section{Notes and references}

1 S. Lee, K. K. Y. Yuen, K. A. Jolliffe and J. Yoon, Chem. Soc. Rev., 2015, 44, 1749-1762.

2 J. F. Zhang, S. Kim, J. H. Han, S. J. Lee, T. Pradhan, Q. Y. Cao, S. J. Lee, C. Kang and J. S. Kim, Org. Lett., 2011, 13, 5294-5297.

3 W. H. Chen, Y. Xing and Y. Pang, Org. Lett., 2011, 13, 1362-1365.

4 N. L. Han, K. M. K. Swamy, K. K. Sook, J. Y. Kwon, Y. Kim, S. J. Kim, J. Y. Yeo and J. Yoon, Org. Lett., 2007, 9, 243-246.

5 D. H. Lee, S. Y. Kim and J. I. Hong, Angew. Chem., Int. Ed., 2004, 43, 4777-4780.

6 J. H. Lee, A. R. Jeong, J. H. Jung, C. M. Park and J. I. Hong, J. Org. Chem., 2011, 76, 417-423.

7 H. N. Lee, Z. Xu, S. K. Kim, K. M. K. Swamy, Y. Kim, S.-J. Kim and J. Yoon, J. Am. Chem. Soc., 2007, 129, 3828-3829.

8 K. K. Y. Yuen and K. A. Jolliffe, Chem. Commun., 2013, 49, 4824-4826.

9 S. J. Butler and K. A. Jolliffe, Org. Biomol. Chem., 2011, 9, 3471-3483.

10 S. K. Kim, D. H. Lee, J.-I. Hong and J. Yoon, Acc. Chem. Res., 2009, 42, 23-31.

11 W. Zhu, X. Huang, Z. Guo, X. Wu, H. Yu and H. Tian, Chem. Commun., 2012, 48, 1784-1786.

12 H. T. Ngo, X. Liu and K. A. Jolliffe, Chem. Soc. Rev., 2012, 41, 4928-4965.
13 A. Ojida, Y. Mito-oka, K. Sada and I. Hamachi, J. Am. Chem. Soc., 2004, 126, 2454-2463.

14 T. Sakamoto, A. Ojida and I. Hamachi, Chem. Commun., 2009, 141-152.

15 S. J. Butler, K. A. Jolliffe, W. Y. G. Lee, M. J. McDonough and A. J. Reynolds, Tetrahedron, 2011, 67, 1019-1029.

16 R. B. P. Elmes and K. A. Jolliffe, Chem. Commun., 2015, 51, 4951-4968.

17 X. Liu, H. T. Ngo, Z. Ge, S. J. Butler and K. A. Jolliffe, Chem. Sci., 2013, 4, 1680-1686.

18 S. J. Butler and K. A. Jolliffe, Chem. - Asian J., 2012, 7, 2621-2628.

19 M. J. McDonough, A. J. Reynolds, W. Y. G. Lee and K. A. Jolliffe, Chem. Commun., 2006, 2971-2973.

20 S. L. Wiskur, P. N. Floriano, E. V. Anslyn and J. T. McDevitt, Angew. Chem., Int. Ed., 2003, 42, 2070-2072.

21 B. P. Morgan, S. He and R. C. Smith, Inorg. Chem., 2007, 46, 9262-9266.

22 M. K. Coggins, A. M. Parker, A. Mangalum, G. A. Galdamez and R. C. Smith, Eur. J. Org. Chem., 2009, 343-348.

23 X. Sun, K. Lacina, E. C. Ramsamy, S. E. Flower, J. S. Fossey, X. Qian, E. V Anslyn, S. D. Bull and T. D. James, Chem. Sci., 2015, 6, 2963-2967.

24 R. G. Hanshaw, S. M. Hilkert, H. Jiang and B. D. Smith, Tetrahedron Lett., 2004, 45, 8721-8724.

25 V. E. Zwicker, X. Liu, K. K. Y. Yuen and K. A. Jolliffe, Supramol. Chem., 2016, 28, 192-200.

26 T. Minami, Y. Liu, A. Akdeniz, P. Koutnik, N. A. Esipenko, R. Nishiyabu, Y. Kubo and P. Anzenbacher, J. Am. Chem. Soc., 2014, 136, 11396-11401.

27 V. E. Zwicker, B. M. Long and K. A. Jolliffe, Org. Biomol. Chem., 2015, 13, 7822-7829.

28 V. V. Rostovtsev, L. G. Green, V. V. Fokin and K. B. Sharpless, Angew. Chem., Int. Ed., 2002, 41, 2596-2599.

29 C. W. Tornøe, C. Christensen and M. Meldal, J. Org. Chem., 2002, 67, 3057-3064. 